\title{
A comparison of DNA sequencing and the hydrolysis probe analysis (TaqMan assay) for knockdown resistance $(k d r)$ mutations in Anopheles gambiae from the Republic of the Congo
}

Kwang Shik Choi ${ }^{1,2 \dagger}$, Belinda L Spillings ${ }^{1,2 \dagger}$, Maureen Coetzee ${ }^{1,2^{*}}$, Richard H Hunt ${ }^{1,3}$, Lizette L Koekemoer ${ }^{1,2}$

\begin{abstract}
Background: Knockdown resistance $(k d r)$ caused by a single base pair mutation in the sodium channel gene is strongly associated with pyrethroid insecticide resistance in Anopheles gambiae in West-Central Africa. Recently, various molecular techniques have been developed to screen for the presence of the $k d r$ mutations in vector populations with varying levels of accuracy. In this study, the results of the hydrolysis probe analysis for detecting the $k d r$ mutations in An. gambiae s.s. from the Republic of the Congo were compared with DNA sequence analysis.

Methods: A total of 52 pyrethroid and DDT resistant An. gambiae from Pointe-Noire (Congo-Brazzaville) were tested for detection of the two kdr mutations (kdr-e and kdr-w) that are known to occur in this species. Results from the hydrolysis probe analysis were compared to DNA sequencing to verify the accuracy of the probe analysis for this vector population.

Results: Fifty-one specimens were found to be An. gambiae S-form and one was a M/S hybrid. DNA sequencing revealed that more than half of the specimens (55.8\%) carried both the $k d r$-e and $k d r-w$ resistance mutations, seven specimens (13.5\%) were homozygous for the kdr-e mutation, and 14 specimens (26.9\%) were homozygous for the kdr-w mutation. A single individual was genotyped as heterozygous kdr-e mutation (1.9\%) only and another as heterozygous kdr-w mutation (1.9\%) only. Analysis using hydrolysis probe analysis, without adjustment of the allelic discrimination axes on the scatter plots, revealed six specimens (11.5\%) carrying both mutations, 30 specimens (57.8\%) as homozygous $k d r-w$, six specimens (11.5\%) homozygous for the $k d r$-e mutation, one specimen (1.9\%) heterozygous for the $k d r-w$ mutation and one specimen (1.9\%) present in wild type form. Eight of the specimens (15.4\%) could not be identified using unadjusted hydrolysis probe analysis values. No heterozygous kdr-e mutations were scored when adjustment for the allelic discrimination axes was omitted. However, when the axes on the scatter plots were adjusted the results were consistent with those of the DNA sequence analysis, barring two individuals that were mis-scored in the hydrolysis probe analysis.
\end{abstract}

Conclusion: Both the kdr-e and kdr-w mutations were abundant in An. gambiae S-form from Pointe-Noire. The hydrolysis probe analysis can lead to misleading results if adjustment to allelic discrimination axes is not investigated. This is mainly relevant when both $k d r-e$ and $k d r-w$ are present in a population in a high frequency. This report highlights the importance of concurrent screening for both mutations. Therefore, performing routine assay protocols blindly can result in the misinterpretation of results. Although hydrolysis probe analysis of $k d r$ is still held as the gold standard assay, this paper highlights the importance of $k d r$ mutation confirmation via sequencing especially in regions where $k d r$ frequency has never been reported before or where both the $k d r-e$ and $k d r-w$ mutations are present simultaneously.

\footnotetext{
* Correspondence: maureenc@nicd.ac.za

+ Contributed equally

'Vector Control Reference Unit, National Institute for Communicable

Diseases of the National Health Laboratory Service, Johannesburg, South

Africa

Full list of author information is available at the end of the article
} 


\section{Background}

One of the main strategies for malaria vector control is the use of pyrethroid insecticides for indoor residual spraying (IRS) and for the impregnation of long-lasting bed nets (LLINs). Reports of insecticide resistance in the major African malaria vectors have increased dramatically over the past few years [1-13]. The monitoring of the presence and development of insecticide resistance in malaria vector populations is essential for understanding resistance mechanisms and for the downstream implementation of insecticide resistance management plans.

Pyrethroids and organochlorines (eg. DDT) target the para-type sodium channel gene in the insect nervous system $[14,15]$. Cross resistance between these two classes of insecticides is reported when mutations in the target site results in insensitivity to these chemicals [16-20].

Two different single nucleotide mutations in the segment 6 of domain II region of the para-type sodium channel gene have been reported in An. gambiae. Martinez-Torres et al [21] reported that the $k d r$ mutation in An. gambiae from West Africa leads to the substitution of a leucine (TTA) for phenylalanine (TTT) (L1014F, $k d r-\mathrm{w})$. Ranson et al [22] reported a second $k d r$ mutation in the same amino acid position in An. gambiae from Kenya. This mutation causes a substitution from leucine (TTA) to serine (TCA) (L1014 S, $k d r$-e) and is referred to as the East African mutation or $k d r$-e. More recently studies have reported heterozygous substitutions for both $k d r$ mutations in $A n$. gambiae from Cameroon (8\% [6]; 1.7\% [7]; 16.1\% [8]), Gabon (55.7\%) [9] and Uganda (1.4\%) [10].

Currently, there are several different assays available for screening the DNA substitutions related to the $k d r$ mutations in An. gambiae. The most commonly used method for detecting the $k d r$-e and $k d r$-w mutations in An. gambiae is carried out using two different allelespecific polymerase chain reaction assays (AS-PCR) $[21,22]$. However, these assays can lead to inaccurate results due to a single nucleotide polymorphism mismatch at the 3'-end of the primer. In order to address the unreliability of this assay, several recent techniques have been developed such as: PCR sequence specific oligonucleotide probe assay (PCR-Dot Blot) [23], Heated Oligonucleotide Ligation Assay (HOLA) [24], Fluorescence Resonance Energy Transfer (FRET)/Melt Curve analysis [10], PCR elongation with fluorescence [25], Sequence Specific Oligonucleotide Probe EnzymeLinked ImmunoSorbent Assay (SSOP-ELISA) [26], hydrolysis probe analysis [27], Primer Introduced Restriction Analysis-PCR assay (PIRA-PCR) [28], multiplex PIRA-PCR assay (mPIRA-PCR) [29] and pyrosequencing [30]. With regard to specificity and sensitivity for detecting the $k d r$ mutations, the hydrolysis probe analysis can be considered to be one of the best [27]. This study shows that this assay remains one of the best assays to use but that both $k d r$ mutations should be screened concurrently. Changing default setting on machine may further enhance the accuracy of results.

\section{Methods}

\section{Mosquito collections and identification}

Fifty two mosquitoes were collected indoors in PointeNoire, Republic of the Congo (Congo-Brazzaville)

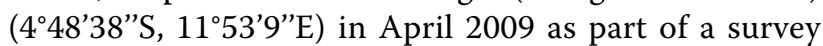
for insecticide resistance. The specimens were identified as An. gambiae s.l. using the keys of Gillies and Coetzee [31]. DNA was extracted from either the abdomen or parts of mosquitoes according to Collins et al [32]. DNA concentration was measured using a NanoDrop spectrophotometer (NanoDrop Technologies) and the amount of DNA varied between 5.1 and $429.9 \mathrm{ng} / \mu \mathrm{L}$. The method of Scott et al [33] was used to identify the specimens to species level and M/S status was determined using a modified method from Favia et al [34].

\section{Hydrolysis probe analysis}

The protocol of Bass et al [27] was used with minor modifications. PCR was performed using a CFX96 ${ }^{\mathrm{TM}}$ Real-Time system (Bio-Rad). Two standard oligonucleotides (Inqaba Biotech) and three minor groove binding (MGB) probes (Applied Biosystems) were used. Primers $k d r$-Forward (5'-CATTTTTCTTGGCCACTGTAGTGAT-3') and $k d r$ Reverse (5'-CGATCTTGGTCCATGTTAATTTGCA-3') were used for binding the flanking region of both $k d r$ mutation sites in the sodium channel gene. The probe WT (5'-CTTACGACTAAATTTC-3') was labelled with VIC for the detection of the wildtype allele and the probes $k d r$ E (5'-ACGACTGAATTTC-3') and $k d r W$ (5'-ACGACAAAATTTC-3') were labelled with 6-FAM for detection of the $k d r$-e and $k d r$-w resistant alleles respectively. The two standard primers ( $k d r$-Forward and $k d r$-Reverse) and the WT probe were used either in one reaction with the $k d r \mathrm{E}$ probe for detecting $k d r$-e or in another reaction with the $k d r W$ probe for detecting $k d r$-w. The $20 \mu \mathrm{L}$ PCR reaction contained $1 \mu \mathrm{L}$ of the genomic DNA of an individual mosquito, $10 \mu \mathrm{L}$ of IQ ${ }^{\mathrm{mm}}$ Supermix (Bio-Rad), $0.8 \mu \mathrm{M}$ of each primer and $0.4 \mu \mathrm{M}$ of each probe. The PCR cycling conditions were as follows: an initial denaturation at $95^{\circ} \mathrm{C}$ for 10 minute, followed by 40 cycles of $95^{\circ} \mathrm{C}$ for $10 \mathrm{sec}-$ onds and $60^{\circ} \mathrm{C}$ for 45 seconds. The increase in VIC and FAM fluorescence was monitored in real time by detecting fluorescence of VIC (560-580 nm detection) and FAM (515-530 nm detection) channels for each dye respectively. The assay was repeated at least twice to ensure that experimental error was limited. 


\section{DNA sequencing}

Genotypes of individuals were confirmed by DNA sequencing. A segment of the $k d r-\mathrm{e}$ and $k d r$-w mutations region in the para-type sodium channel gene from 52 individuals was amplified using Agd1 (5'-ATAG ATTCCCCGACCATG-3') and Agd2 (5'-AGACAAGG ATGATGAACC-3') primers [21]. A total volume of 50 $\mu \mathrm{L}$ for each reaction contained average $91.3 \mathrm{ng}$ genomic DNA of an individual mosquito, $1 \times$ PCR Buffer, $1.5 \mathrm{mM}$ $\mathrm{MgCl}_{2}, 0.2 \mathrm{mM}$ of each dNTP, $0.4 \mu \mathrm{M}$ of each primer, and 1 unit of Taq DNA polymerase. The cycling conditions were as follows: a 2 minute $94{ }^{\circ} \mathrm{C}$ denaturation step; 40 cycles of 30 seconds at $94{ }^{\circ} \mathrm{C}, 30$ seconds at $50^{\circ}$ $\mathrm{C}$ and 30 seconds at $72^{\circ} \mathrm{C}$; final extension for 5 minutes at $72^{\circ} \mathrm{C}$. The PCR products were electrophoresed on $1.5 \%$ agarose gel containing $0.5 \mu \mathrm{g} / \mathrm{mL}$ ethidium bromide. Direct PCR sequencing was performed by MACROGEN (Seoul, Korea) for both strands using the Adg1 and Agd2 primers. The results were aligned and analysed using Clustal $\mathrm{X}$ and Bioedit.

\section{Results}

Of the 52 specimens used, 51 were An. gambiae S-forms and one individual was identified as a hybrid M/S. This was confirmed using DNA sequencing as well as the method of Fanello et al [35]. The hybrid M/S specimen carried both $k d r$ mutations. No M-form specimens were identified in this study. Comparison between the hydrolysis probe analysis (default setting for the allelic discrimination axes) and DNA sequencing revealed that only $51.9 \%$ for the $k d r$-e and $86.5 \%$ for the $k d r$-w gave similar results (Table 1). For this reason the axes used for allelic discrimination were adjusted and data re-analysed.

\section{Hydrolysis probe analysis}

The first specific probe for the wild type allele was labelled with VIC and the second specific probe for the $k d r$-e or $k d r$-w alleles was labelled with FAM. It was essential to determine the standard values of fluorescence for scoring the genotypes in order to produce accurate results. The results from the hydrolysis probe analysis in this study were only consistent with the results from the DNA sequence when the allelic discrimination axes were adjusted (10\% and $65 \%$ for the $k d r$-e allele susceptible and resistant probes with VIC and FAM respectively and $35 \%$ for the $k d r$-w resistant probe with FAM) from the original default axes as determined by the hydrolysis probe analysis programme were performed (Figure 1). No adjustment was needed for the wild type susceptible probe when it was run in the $k d r$-w reaction. One sample was identified as RR using $k d r$-w probe, while this specimen gave a failed reaction when using $k d r$-e analysis upon sequencing. This sample was shown to be homozygous for both $k d r$-e and $k d r$-w mutations. A second sample failed in $k d r$-w analysis, but was identified as RR using the $k d r$-e analysis. This specimen was also sequenced and shown as homozygous for both $k d r$-e and $k d r$-w. Therefore, $2 / 52$ or $4 \%$ of samples resulted in discrepancies between the sequence and hydrolysis probe results. Adjustment of the allelic discrimination axes did not alter this result.

\section{DNA sequencing}

The region for the $k d r$ mutations in the sodium channel gene sequenced includes $293 \mathrm{bp}$ of coding region. The results were aligned with each of the allele sequences from GenBank. The data showed 55.8\% (29/52) of specimens carried both the $k d r$-e and $k d r-\mathrm{w}$ mutations in heterozygote form. Seven specimens were homozygous for the $k d r$-e mutation and 14 homozygous for the $k d r$ $\mathrm{w}$ mutation. There was only one specimen heterozygous for the $k d r$-e mutation and one other that was heterozygous for the $k d r-w$ mutation. Sequence analysis did not reveal any homozygous susceptible specimens for both $k d r$ mutations i.e. the wild type form.

\section{Discussion}

Most of the specimens collected in Pointe-Noire were An. gambiae S-form (98.1\%). Unexpectedly, one specimen was identified as a hybrid M/S whilst no An. gambiae M-form were collected in this study area. Koekemoer et al (Multiple insecticide resistance in Anopheles gambiae (Diptera: Culicidae) from Pointe Noire, Republic of the Congo, submitted) published additional data from this area from 343 specimens. This was the only hybrid identified from large sample analysis and additional genetic studies would need to be concluded to explain the presence of the hybrid in the rare presence of An. gambiae M-form $(0.3 \%)$ by performing analysis of large sample size. The presence of the $k d r$ mutations within this study cohort was unexpectedly high (100\% of sequenced samples; $96 \%$ of hydrolysis probe analysis samples). Both $k d r$-e and $k d r$ $\mathrm{w}$ resistance mutations occurred simultaneously in $29(55.8 \%)$ out of 52 specimens. The frequencies of the homozygous $k d r$-e and $k d r$-w single mutations were 7 (13.5\%) and 14 specimens (26.9\%) respectively. There was one specimen heterozygous for the $k d r$-e $(1.9 \%)$ and another heterozygous for the $k d r-\mathrm{w}(1.9 \%)$ mutations. Although recent studies reported that the frequencies of the both mutations present at the same time were much lower (1.7-16.1\% in Cameroon [6-8] and 1.4\% in Uganda [10]) than the present study, Pinto et al [9] reported that all An. gambiae specimens collected in Gabon in 2000 carried the $k d r$-e or $k d r$-w mutations and $55.7 \%$ of the cooccurring both mutations. A recent study has reported that the An. gambiae population from Congo was resistant to DDT (100\%), deltamethrin (26\%), dieldrin (69\%) and bendiocarb (3\%) (Koekemoer et al: Multiple insecticide 
Table 1 Comparison of the frequency of the $k d r-e$ and $k d r-w$ mutations using DNA sequence, and hydrolysis probe analysis with and without adjustment of the allelic discrimination axes

\begin{tabular}{lllllll}
\hline & & \multicolumn{3}{c}{ Genotypes } \\
Detection method & Ser-Phe & Ser-Ser & Phe-Phe & Ser-Leu & Phe-Leu & No ID \\
\hline DNA sequence & 29 & 7 & 14 & 1 & 1 & 0 \\
& $(55.8 \%)$ & $(13.5 \%)$ & $(26.9 \%)$ & $(1.9 \%)$ & $(1.9 \%)$ & $(0 \%)$ \\
Hydrolysis probe analysis without adjustment & 6 & 6 & 30 & 1 & 1 & 8 \\
& $(11.5 \%)$ & $(11.5 \%)$ & $(57.8 \%)$ & $(1.9 \%)$ & $(1.9 \%)$ & $(15.4 \%)$ \\
Hydrolysis probe analysis with adjustment & 27 & 8 & 15 & 1 & 1 & 0 \\
& $(51.9 \%)$ & $(15.4 \%)$ & $(28.9 \%)$ & $(1.9 \%)$ & $(1.9 \%)$ & $(0 \%)$ \\
\hline
\end{tabular}

A total samples were 52 specimens. Ser = L1014 S $(k d r-e) ;$ Phe = L1014F $(k d r-w) ;$ Leu = Wild type; No ID = failed to amplify.
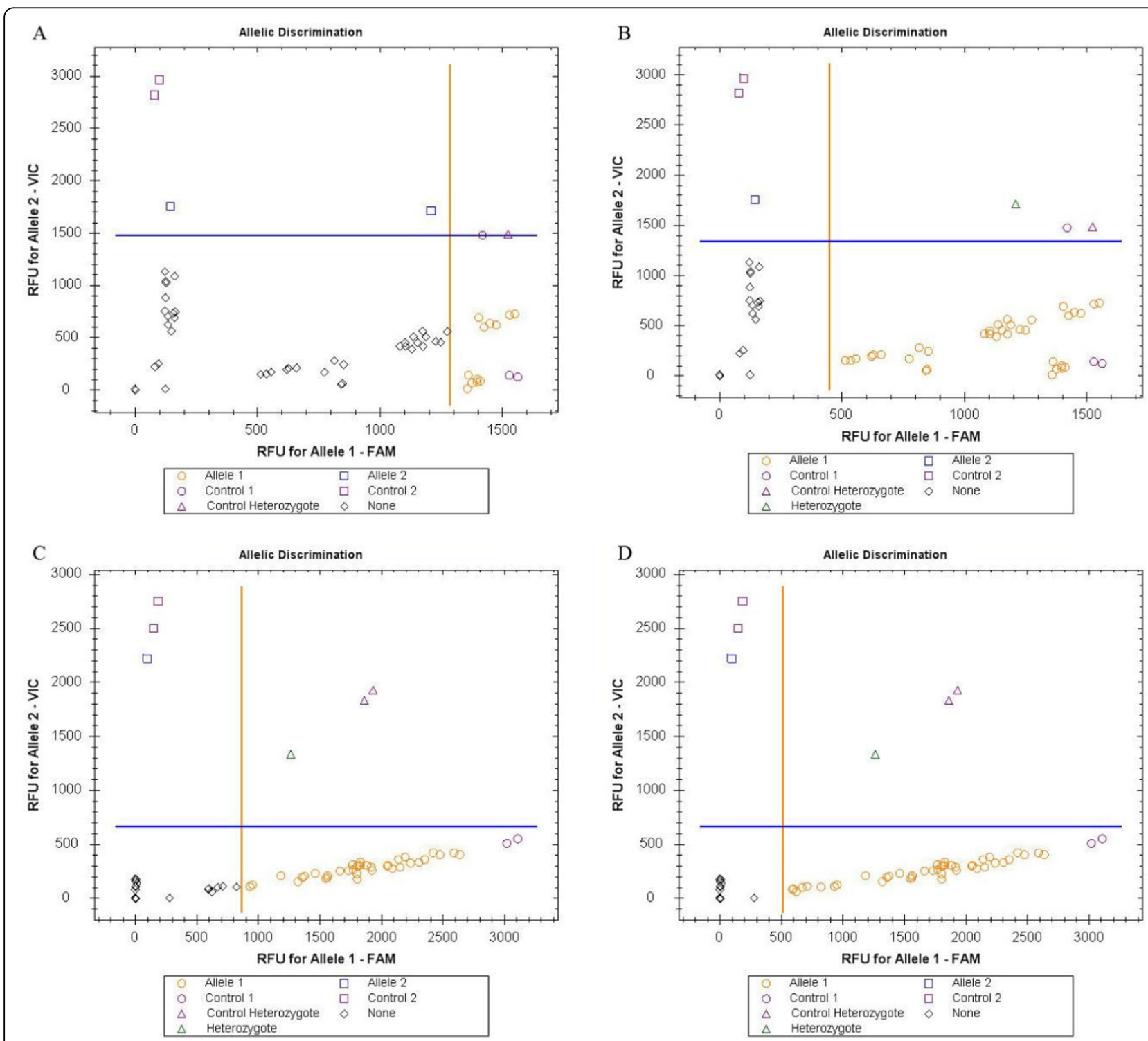

Figure 1 Scatter plot analysis of hydrolysis probe analysis fluorescence results for the $k d r$-e and $k d r$-w assays before and after adjustment of the allelic discrimination axes. A) The default allelic discrimination axes for the kdr-e mutation assay. B) After adjusting the allelic discrimination axes for the kdr-e mutation assay were shown. C) The default allelic discrimination axes for the kdr-w mutation assay. D) After adjusting the allelic discrimination axis for the FAM only. 
resistance in Anopheles gambiae (Diptera: Culicidae) from Pointe Noire, Republic of the Congo, submitted). This study also suggested that both $k d r$ mutations in An. gambiae are widespread in the region.

Although DNA sequencing remains the most accurate method for detecting the presence of $k d r$ mutations, it is much more time consuming and expensive ( $>$ US $\$ 10$ per sample for sequencing in both directions) than other assays. Bass et al [27] reported that the hydrolysis probe analysis is the most sensitive and specific assay for detecting $k d r$ mutations $(5.2 \%$ of failed reactions and $0 \%$ of mis-scores) when compared to AS-PCR, HRM, HOLA, SSOP-ELISA and PCR-Dot Blot assays even though the cost of the assay (US\$1.72 per sample) is higher than some of the other methods (US\$0.62 - US\$ 1.74 per sample). In this study, $4 \%(2 / 52)$ samples gave different results between the hydrolysis probe and sequencing assays due to a failed reaction of either the $k d r$-e or $k d r$-w PCR.

Results from this study recommend that the allelic discrimination axes used for detecting both mutations simultaneously can be adjusted to increase sensitivity of the assay. This is especially true in those populations carrying both mutations at high frequency. However, this decision should be made cautiously and sequencing should be used to validate the adjustments made.

The accuracy of the assay could fluctuate due to the determination of the allelic discrimination values for the axes as well as due to other variable running conditions. A number of conditions such as quality and quantity of DNA templates, master mixes, PCR assay performers, the positioning of the allelic discrimination axes and other conditions might affect $k d r$ genotyping. The best method for genotyping seems to be end point analysis as well as intensity of fluorescence, although two out of fifty two samples in this study could not be genotyped using these values due to misleading RFU values, even after adjustment of the default allelic discrimination axes.

\section{Conclusions}

Various new assays have been developed to screen $k d r$ mutations in An. gambiae and the hydrolysis probe analysis is a preferred method. As this assay becomes more widely used in African laboratories it is important to emphasize that accurate genotyping in An. gambiae will rely on concurrent testing of both $k d r$-e and $k d r$-w mutations. In addition, this should be noted that default settings might have to be adjusted to enhance results.

\section{Conflict of interests}

The authors declare that they have no competing interests.

\section{Authors' contributions}

KSC carried out identification of species and molecular forms of $A n$. gambiae, $k d r-e$ and $k d r-w$ assays and DNA sequence, analysed the data and drafted the manuscript. BLS contributed to the design of this study, carried out identification of species, repetition of both $k d r$ mutation assays, helped analyse the data and draft the manuscript. $\mathrm{RHH}$ collected all specimens from Pointe-Noire, identified species morphologically and helped draft the manuscript. LLK and MC assisted in data analysis and drafting of the manuscript.

All authors have read and approved the final manuscript.

\section{Acknowledgements}

This work was supported by the National Health Laboratory Service and received financial aid from the National Research Foundation (NRF) and the University of the Witwatersrand. MC was supported by a DST/NRF South African Research Chair Initiative grant. We are grateful to Dr. C. Bass for supplying positive controls used in this study.

\section{Author details}

${ }^{1}$ Vector Control Reference Unit, National Institute for Communicable Diseases of the National Health Laboratory Service, Johannesburg, South Africa. ${ }^{2}$ Malaria Entomology Research Unit, School of Pathology, Faculty of Health Sciences, University of the Witwatersrand, Johannesburg, South Africa. ${ }^{3}$ School of Animal, Plant and Environmental Sciences, University of the Witwatersrand, Johannesburg, South Africa.

Received: 25 June 2010 Accepted: 12 October 2010 Published: 12 October 2010

\section{References}

1. Hargreaves K, Koekemoer LL, Brooke BD, Hunt RH, Mthembu J, Coetzee M: Anopheles funestus resistant to pyrethroid insecticides in South Africa. Med Vet Entomol 2000, 14:181-189.

2. Diabate A, Baldet T, Chandre F, Akoobeto M, Guiguemde TR, Darriet F, Brengues C, Guillet P, Hemingway J, Small GJ, Hougard JM: The role of agricultural use of insecticides in resistance to pyrethroids in Anopheles gambiae s.l. in Burkina Faso. Am J Trop Med Hyg 2002, 67:617-622.

3. Diabate A, Baldet T, Chandre F, Dabire KR, Kengne P, Guiguemde TR, Simard F, Guillet P, Hemingway J, Hougard JM: Kdr mutation, a genetic marker to assess events of introgression between the molecular $\mathrm{M}$ and $\mathrm{S}$ forms of Anopheles gambiae (Diptera: Culicidae) in the tropical savannah area of West Africa. J Med Entomol 2003, 40:195-198.

4. Stump AD, Atieli FK, Vulule JM, Besansky NJ: Dynamics of the pyrethroid knockdown resistance allele in western Kenyan populations of Anopheles gambiae in response to insecticide-treated bed net trials. Am J Trop Med Hyg 2004, 70:591-596.

5. Tripet F, Wright J, Lanzaro G: A new high-performance PCR diagnostic for the detection of pyrethroid knockdown resistance $k d r$ in Anopheles gambiae. Am J Trop Med Hyg 2006, 74:658-662.

6. Etang J, Fondjo E, Chandre F, Morlais I, Brengues C, Nwane P, Chouaibou M, Ndjemai $H$, Simard F: First report of knockdown mutations in the malaria vector Anopheles gambiae from Cameroon. Am J Trop Med Hyg 2006, 74:795-797.

7. Ndjemaï HNM, Patchoké S, Atangana J, Etang J, Simard F, Bilong Bilong CF, Reimer L, Cornel A, Lanzaro GC, Fondjo E: The distribution of insecticide resistance in Anopheles gambiae s.l. populations from Cameroon: an update. Trans R Soc Trop Med Hyg 2009, 103:1127-1138.

8. Nwane P, Etang J, Chouaibou M, Toto JC, Kerah-Hinzoumbe C, Mimpfoundi R, Awono-Ambene HP, Simard F: Trends in DDT and pyrethroid resistance in Anopheles gambiae s.s. populations from urban and agro-industrial settings in southern Cameroon. BMC Infect Dis 2009, 9:163.

9. Pinto J, Lynd A, Elissa N, Donnelly MJ, Costa C, Gentile G, Caccone A, do Rosário VE: Co-occurrence of East and West African $k d r$ mutations suggests high levels of resistance to pyrethroid insecticides in Anopheles gambiae from Libreville, Gabon. Med Vet Entomol 2006, 20:27-32.

10. Verhaeghen K, Van Bortel W, Roelants P, Backeljau T, Coosemans M: Detection of the East and West African kdr mutation in Anopheles gambiae and Anopheles arabiensis from Uganda using a new assay based on FRET/Melt Curve analysis. Malar J 2006, 5:16.

11. Santolamazza F, Calzetta M, Etang J, Barrese E, Dia I, Caccone A, Donnelly MJ, Petrarca V, Simard F, Pinto J, della Torre A: Distribution of knock-down resistance mutations in Anopheles gambiae molecular forms in west and west-central Africa. Malar J 2008, 7:74. 
12. Mouatcho JC, Munhenga G, Hargreaves K, Brooke BD, Coetzee M, Koekemoer LL: Pyrethroid resistance in a major African malaria vector Anopheles arabiensis from Mamfene, northern KwaZulu/Natal, South Africa. S Afr J Sci 2009, 105:127-131

13. Ranson H, Abdallah H, Badolo A, Guelbeogo WM, Kerah-Hinzoumbe C, Yangalbe-Kalnone E, Sagnon N'f, Simard F, Coetzee M: Insecticide resistance in Anopheles gambiae: data from the first year of a multicountry study highlight the extent of the problem. Malar J 2009, 8:299.

14. Soderlund DM, Bloomquist JR: Neurotoxic actions of pyrethroid insecticides. Ann Rev Entomol 1989, 34:77-96.

15. Narahashi T: Nerve membranes $\mathrm{Na}^{+}$channels as targets of insecticides. Trends Pharmacol Sci 1992, 13:236-241.

16. Williamson MS, Martinez-Torres D, Hick CA, Devonshire AL: Identification of mutations in the housefly para-type sodium channel gene associated with knockdown resistance $(k d r)$ to pyrethroid insecticides. Mol Gen Genet 1996, 252:51-60.

17. Dong $\mathrm{K}: \mathrm{A}$ single amino acid change in the para sodium channel protein is associated with knock-down resistance $(k d r)$ to pyrethroid insecticides in German cockroach. Insect Biochem Mol Biol 1997, 27:93-100.

18. Park Y, Taylor MJF: A novel mutation L1029 H in sodium channel gene hscp associated with pyrethroid resistance for Heliothis virescens (Lepidoptera: Noctuidae). Insect Biochem Mol Biol 1997, 27:9-13.

19. Jamroz RC, Guerrero FD, Kammlah DM, Kunz SE: Role of the $k d r$ and super$k d r$ sodium channel mutations in pyrethroid resistance: correlation of allelic frequency to resistance level in wild and laboratory populations of horn flies (Haematobia irritans). Insect Biochem Mol Biol 1998, 28:1031-1037.

20. Martinez-Torres D, Foster SP, Field LM, Devonshire AL, Williamson MS: A sodium channel point mutation is associated with resistance to DDT and pyrethroid insecticides in the peach-potato aphid, Myzus persicae. Insect Mol Biol 1999, 8:39-46.

21. Martinez-Torres D, Chandre F, Williamson MS, Darriet F, Berge JB, Devonshire AL, Guillet P, Pasteur N, Pauron D: Molecular characterization of pyrethroid knockdown resistance $(k d r)$ in the major malaria vector Anopheles gambiae s.s. Insect Mol Biol 1998, 7:179-184.

22. Ranson $H$, Jensen $B$, Vulule JM, Wang $X$, Hemingway J, Collins FH: Identification of a point mutation in the voltage-gated sodium channel gene of Kenyan Anopheles gambiae associated with resistance to DDT and pyrethroids. Insect Mol Biol 2000, 9:491-497.

23. Kolaczinski JH, Fanello C, Herve JP, Conway DJ, Carnevale P, Curtis CF: Experimental and molecular genetic analysis of the impact of pyrethroid and non-pyrethroid insecticide impregnated bednets for mosquito control in an area of pyrethroid resistance. Bull Entomol Res 2000, 90:125-132.

24. Lynd A, Ranson H, McCall PJ, Randle NP, Black WC, Walker ED, Donnelly MJ: A simplified high-throughput method for pyrethroid knock-down resistance (kdr) detection in Anopheles gambiae. Malar J 2005, 4:16.

25. Tripet F, Wright J, Lanzaro G: A new high-performance PCR diagnostic for the detection of pyrethroid knockdown resistance $k d r$ in Anopheles gambiae. Am J Trop Med Hyg 2006, 74:658-662.

26. Kulkarni MA, Rowland M, Alifrangis M, Mosha FW, Matowo J, Malima R, Peter J, Kweka E, Lyimo I, Magesa S, Salanti A, Rau ME, Drakeley C: Occurrence of the leucine-to-phenylalanine knockdown resistance $(k d r)$ mutation in Anopheles arabiensis populations in Tanzania, detected by a simplified high-throughput SSOPELISA method. Malar J 2006, 5:56.

27. Bass C, Nikou D, Donnelly MJ, Williamson MS, Ranson H, Ball A, Vontas J, Field L: Detection of knockdown resistance $(k d r)$ mutations in Anopheles gambiae: a comparison of two new high-throughput assays with existing methods. Malar J 2007, 6:111.

28. Janeira F, Vicente JL, Kanganje Y, Moreno M, Do Rosário VE, Cravo P, Pinto J: A primer-introduced restriction analysis-polymerase chain reaction method to detect knockdown resistance mutations in Anopheles gambiae. J Med Entomol 2008, 45:237-241.

29. Kazanidou A, Nikou D, Grigoriou M, Vontas J, Skavdis G: Short report: A multiplex PCR assay for simultaneous genotyping of $k d r$ and ace- 1 loci in Anopheles gambiae. Am J Trop Med Hyg 2009, 80:236-238.

30. Vezenegho SB, Brooke BD, Hunt RH, Coetzee M, Koekemoer LL: Malaria vector composition and insecticide susceptibility status in Guinea Conakry, West Africa. Med Vet Entomol 2009, 23:326-334.
31. Gillies MT, Coetzee M: A Supplement to the Anophelinae of Africa South of the Sahara (Afrotropical Region). Publications of the South African Institute for Medical Research, Johannesburg, South Africa 1987, 55.

32. Collins FH, Mendez MA, Rasmussen MO, Meheffey PC, Besansky NJ, Finnerty $\mathrm{V}$ : A ribosomal RNA gene probes differentiates members of the Anopheles gambiae complex. Am J Trop Med Hyg 1987, 37:37-41.

33. Scott JA, Brogdon WG, Collins FH: Identification of single specimens of the Anopheles gambiae complex by the polymerase chain reaction. Am J Trop Med Hyg 1993, 49:520-529.

34. Favia G, Lanfrancotti A, Spanos L, Sidén-Kiamos I, Louis C: Molecular characterization of ribosomal DNA polymorphisms discriminating among chromosomal forms of Anopheles gambiae s.s. Insect Mol Biol 2001, 10:19-23.

35. Fanello C, Santolamazza F, della Torre A: Simultaneous identification of species and molecular forms of the Anopheles gambiae complex by PCRRFLP. Med Vet Entomol 2002, 16:461-464.

\section{doi:10.1186/1475-2875-9-278}

Cite this article as: Choi et al:: A comparison of DNA sequencing and the hydrolysis probe analysis (TaqMan assay) for knockdown resistance ( $k d r)$ mutations in Anopheles gambiae from the Republic of the Congo. Malaria Journal 2010 9:278.

\section{Submit your next manuscript to BioMed Central and take full advantage of:}

- Convenient online submission

- Thorough peer review

- No space constraints or color figure charges

- Immediate publication on acceptance

- Inclusion in PubMed, CAS, Scopus and Google Scholar

- Research which is freely available for redistribution

Submit your manuscript at www.biomedcentral.com/submit
C Biomed Central 